\title{
Targeting HOX transcription factors in prostate cancer
}

\author{
Richard Morgan ${ }^{*}$, Angie Boxall ${ }^{1}$, Kevin J Harrington², Guy R Simpson ${ }^{1}$, Agnieszka Michael ${ }^{1}$ and Hardev S Pandha ${ }^{1}$
}

\begin{abstract}
Background: The HOX genes are a family of transcription factors that help to determine cell and tissue identity during early development, and which are also over-expressed in a number of malignancies where they have been shown to promote cell proliferation and survival. The purpose of this study was to evaluate the expression of HOX genes in prostate cancer and to establish whether prostate cancer cells are sensitive to killing by HXR9, an inhibitor of HOX function.
\end{abstract}

Methods: HOX function was inhibited using the HXR9 peptide. HOX gene expression was assessed by RNA extraction from cells or tissues followed by quantitative PCR, and siRNA was used to block the expression of the HOX target gene, cFos. In vivo modelling involved a mouse flank tumour induced by inoculation with LNCaP cells.

Results: In this study we show that the expression of HOX genes in prostate tumours is greatly increased with respect to normal prostate tissue. Targeting the interaction between HOX proteins and their PBX cofactor induces apoptosis in the prostate cancer derived cell lines PC3, DU145 and LNCaP, through a mechanism that involves a rapid increase in the expression of CFOS, an oncogenic transcription factor. Furthermore, disrupting HOX/PBX binding using the HXR9 antagonist blocks the growth of LNCaP tumours in a xenograft model over an extended period.

Conclusion: Many HOX genes are highly over-expressed in prostate cancer, and prostate cancer cells are sensitive to killing by HXR9 both in vitro and in vivo. The HOX genes are therefore a potential therapeutic target in prostate cancer.

Keywords: Prostate cancer, HXR9, HOX, PBX

\section{Background}

Prostate cancer is the most prevalent male malignancy with just under one million new cases worldwide each year [1]. Treatment pathways for this disease are relatively well defined and include surgery, radiotherapy and/or hormonal therapy. While the majority of patients with early stage disease are cured, $10-15 \%$ patient still develop locally recurrent or metastatic disease and have a significantly reduced survival rate [2]. Despite the general adoption of docetaxel chemotherapy agents and novel agents such as abiraterone [3], there is still an urgent need to develop effective new treatments, and therefore it is necessary to explore new target proteins and intracellular signalling pathways.

\footnotetext{
* Correspondence: r.morgan@surrey.ac.uk

${ }^{1}$ Faculty of Health and Medical Sciences, University of Surrey, Guildford, UK Full list of author information is available at the end of the article
}

Recently, considerable interest has been shown in genes that play key roles in defining the identity of cells and tissues in early development and which therefore also have important regulatory roles in cell proliferation and survival. One group of genes that fit into this category are the $H O X$ family of transcription factors [4]. HOX proteins are characterised in part by a highly conserved homeodomain that mediates DNA binding, together with a defined set of co-factors that modify their function including members of PBX family [5-7]. The pro-proliferative and anti-apoptotic roles of some $H O X$ genes in development make them potential oncogenes, and indeed there are numerous reports of $H O X$ overexpression in a range of malignancies, including prostate cancer [4,8-11]. Although definitive oncogenic roles for some $H O X$ genes have been described, in general studies on the function of individual $H O X$ genes in cancer have 
been complicated by the high levels of sequence identity and functional redundancy exhibited by most members $[12,13]$. This functional redundancy in particular has made the results of conventional knock-down studies (using for example siRNA) hard to interpret. As an alternative approach we developed a peptide, HXR9 that acts as a competitive antagonist of the interaction between HOX proteins and their PBX co-factor. This interaction is mediated by a conserved hexapeptide sequence shared by the majority of HOX proteins, and HXR9 can globally repress HOX function through mimicking this peptide [14-22]. In this study we show that prostate tumours have a highly dysregulated pattern of $H O X$ expression and that HXR9 induces apoptosis in prostate cancer derived cell lines through a mechanism that involves a rapid increase in expression of the $c F o s$ gene. Furthermore, HXR9 can block prostate tumour growth in vivo for an extended period, suggesting that HXR9 or its derivatives might represent a possible therapeutic option for locally recurrent prostate cancer.

\section{Methods}

\section{Cell lines and culture}

The cell lines used in this study were DU145 (derived from a prostate carcinoma brain metastasis) [23], PC3 (derived from a prostate adenocarcinoma bone metastasis) [24], LNCaP (derived from a prostate carcinoma lymph node metastasis)[25], and WPMY-1 (derived from normal prostate stroma and immortalised with SV40 Large $\mathrm{T}$ antigen) [26]. They were obtained from the ATCC through LGC Standards Ltd (UK), and were cultured according to the instructions on the LGC Standards website.

\section{Synthesis of HXR9 and CXR9 peptides}

HXR9 is an 18 amino acid peptide consisting of the previously identified hexapeptide sequence that can bind to PBX and nine C-terminal arginine residues (R9) that facilitate cell entry. The $\mathrm{N}$-terminal and $\mathrm{C}$-terminal amino bonds are in the $\mathrm{D}$-isomer conformation, which has previously been shown to extend the half-life of the peptide to 12 hours in human serum [19]. CXR9 is a control peptide that includes the R9 sequence but lacks a functional hexapeptide sequence due to a single alanine substitution. All peptides were synthesized using conventional column based chemistry and purified to at least $80 \%$ (Biosynthesis Inc, USA). The sequences of the peptides are as follows:

HXR9: WYPWMKKHHRRRRRRRRR (2700.06 Da) CXR9: WYPAMKKHHRRRRRRRRR (2604.14 Da)

\section{Primary prostate tumour RNA}

Total RNA from prostate tumours and normal prostate tissue was obtained from OriGene Technologies Ltd,
Rockville, USA. Six normal prostate tissue samples (median age of donor 56 years, range 52-71 years), and 17 prostate tumour samples (median age of donor 60 years, range 48-73 years) were included in the analysis. Of the prostate tumour samples, 5 were Gleason grade 6, 8 were Gleason grade 7, 1 was Gleason grade 8, and 3 were Gleason grade 9. Reverse transcription and QPCR were performed as described below.

\section{RNA purification and reverse transcription}

Total RNA was isolated from cells using the RNeasy Plus Mini Kit (Qiagen) by following the manufacturer's protocol. The RNA was denatured by heating to $65^{\circ} \mathrm{C}$ for 5 minutes. cDNA was synthesized from RNA using the Cloned AMV First Strand Synthesis Kit (Invitrogen) according to the manufacturer's instructions.

\section{Quantitative PCR}

Quantitative PCR was done using the Stratagene MX3005P real-time PCR machine and the Brilliant SYBR Green QPCR Master Mix (Stratagene). Oligonucleotide primers were designed to facilitate the unique amplification of $\beta$-actin, c-Fos, and each HOX gene. The expression of each gene was calculated using the ${ }^{\Delta \Delta} \mathrm{Ct}$ method.

\section{Mice and in vivo trial}

All animal experiments were conducted in accordance with the United Kingdom Co-ordinating Committee on Cancer Research (UKCCCR) guidelines for the Welfare of Animals in Experimental Neoplasia [27]. The experimental protocol was approved by the University of Surrey Animal Welfare Ethical Review Board, and by the UK Home Office (licence number 70/7347).

Athymic nude mice were kept in positive pressure isolators in 12 hour light/dark cycles and food and water were available ad libitum. Mice were inoculated subcutaneously with a suspension of $2.5 \times 10^{6} \mathrm{LNCaP}$ cells in culture media $(100 \mu \mathrm{l})$. Once tumours reached volumes of approximately $100 \mathrm{~mm}^{3}$, mice received an initial, single intratumoural dose of $100 \mathrm{mg} / \mathrm{Kg}$ CXR9 or HXR9 dissolved in $0.1 \mathrm{ml}$ PBS, with subsequent dosing when or if the tumour reoccurred. The HXR9 and CXR9 treatment groups contained 9 and 8 mice, respectively. The mice were monitored carefully for signs of distress, including behavioural changes and weight loss.

\section{Results}

Multiple HOX genes are dysregulated in prostate tumours and cell lines

Previous studies have revealed that HOX genes are generally dysregulated in malignant tissue compared to normal adult cells, and we investigated whether this is also the case in prostate cancer. In order to do this we 
obtained RNA from three cell lines derived from prostate cancer; DU145 [23], PC3 [24] and LNCaP [25], and a cell line derived from non-malignant prostate stromal cells, WPMY-1 [26]. QPCR analysis of expression levels of all $39 H O X$ genes shows that the tumour derived cell lines have significantly different patterns of HOX expression compared to WMPY-1. In particular, the cancerderived lines all show higher expression of the $H O X C$ genes and of HOXB5 and HOXB7, whilst WMPY-1 expresses $H O X$ genes closer to the $5^{\prime}$ (posterior) end of each $H O X$ cluster (Figure 1).

\section{The HOX/PBX antagonist HXR9 is cytotoxic to prostate cancer derived cell lines}

Given the elevated expression of HOX genes in both primary prostate tumours and cell lines, we assessed whether the prostate cancer-derived cell lines LNCaP, DU145 and PC3 were sensitive to killing by the HOX/ PBX antagonist HXR9. HXR9 is an 18 amino acid peptide that can enter cells via endocytosis mediated by a polyarginine sequence. A fluorescently labelled version of this peptide was taken up by all of the cell lines tested (Figure 2a), and could be detected in both the cytoplasm and the nucleus. As a negative control, we used a second peptide, CXR9, which is identical to HXR9 with the exception of a single alanine substitution in the hexapeptide sequence. PC3 cells treated with $60 \mu \mathrm{M}$ CXR9 for two hours do not exhibit any apparent cytotoxicity compared to untreated cells (Figure 2b, c), whilst the same concentration of HXR9 results in extensive cell death (Figure 2d).

The cytotoxicity of HXR9 and CXR9 was determined for all three cancer-derived lines and the non-malignant line WPMY-1 using an MTS assay. This revealed that all three of the lines were sensitive to killing by HXR9, whilst WPMY-1 cells were significantly less sensitive (Figure 2e, f).

\section{HXR9 induces apoptosis in prostate cancer derived cell lines}

To further understand the mechanism of HXR9-induced cell death, we studied the activity of caspase 3 in HXR9treated cells. Caspase 3 is a key component of both the intrinsic and extrinsic apoptotic pathway, and can cleave a group of proteins involved in cell survival and proliferation. All of the prostate cancer derived cell lines showed a significant increase in caspase 3 activity when treated with $60 \mu \mathrm{M}$ HXR9 for two hours (3.7 fold for PC3 cells and 4.8 fold for both DU145 and LNCaP cells), whilst WPMY-1 cells do not (1.4 fold increase, $\mathrm{p}=0.0972$ ). Treatment with CXR9 did not change caspase 3 activity in any of the cell lines (Figure $3 a$ ).

To further explore whether HXR9 induces cell death primarily through apoptosis, we also used a FACS based analysis for changes in the cell membrane that are characteristic of process and which can be detected by fluorescently labelled Anexxin. The assay also utilises a fluorescent DNA label (7AAD) to measure the membrane

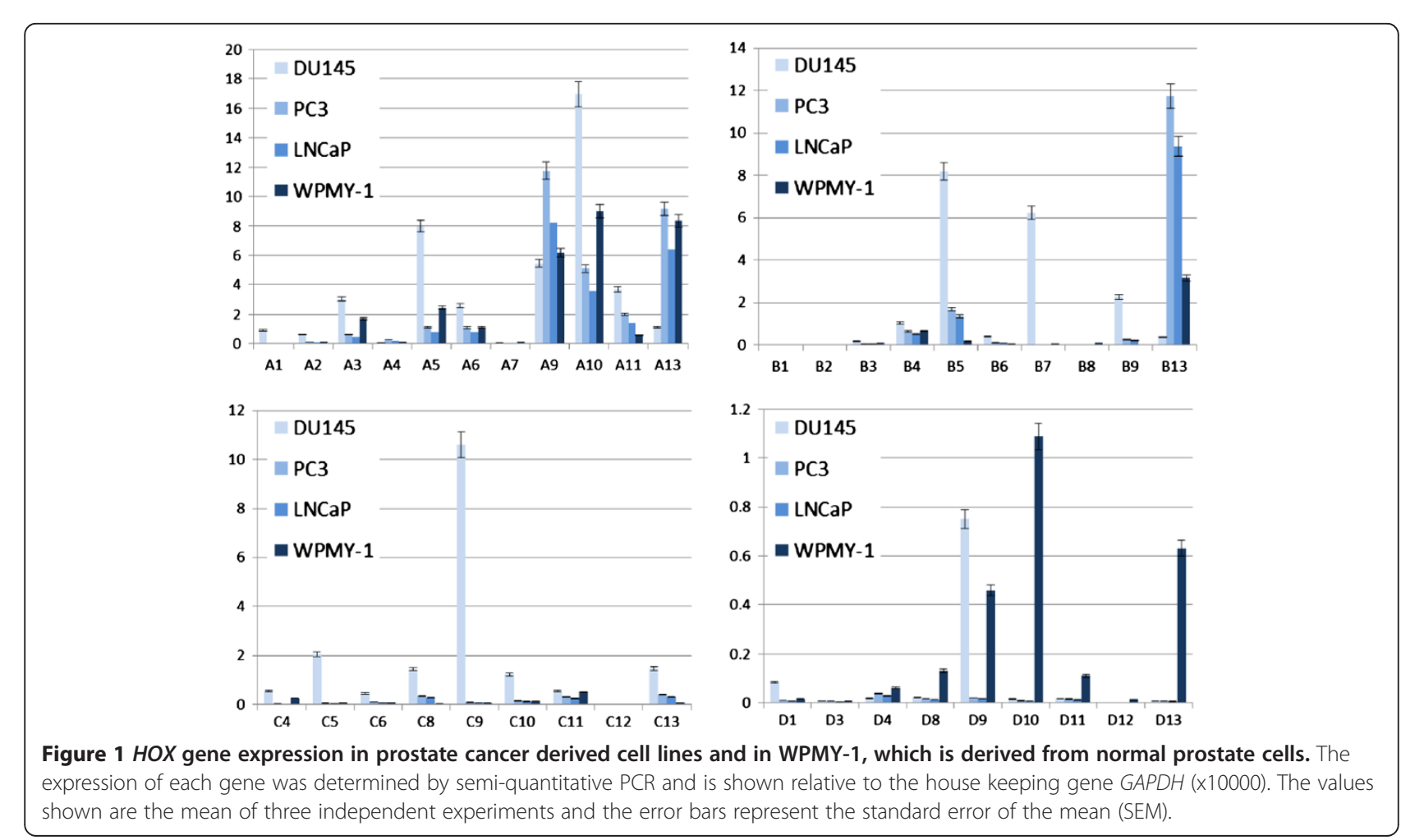



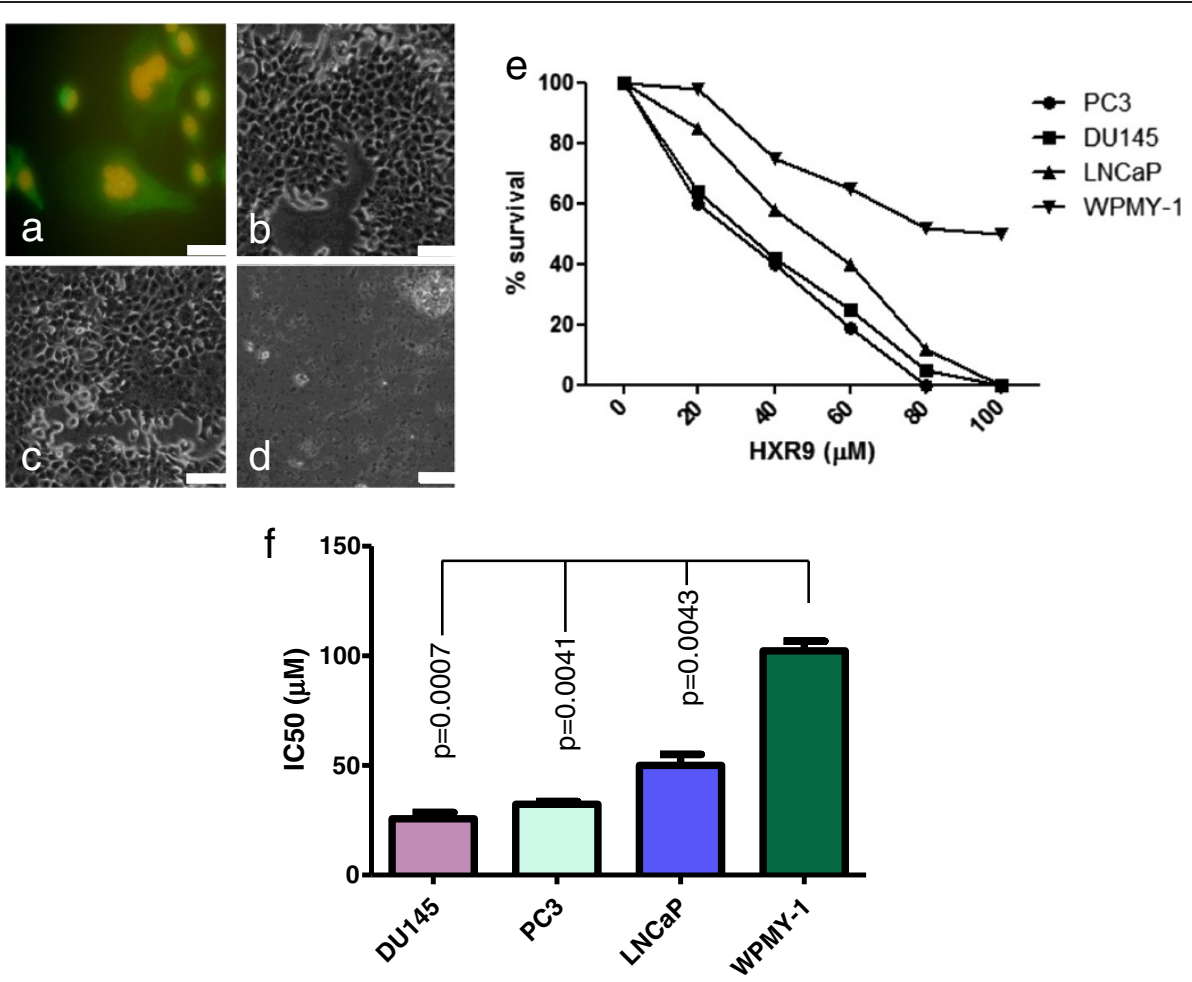

Figure 2 Prostate cancer-derived cell lines are sensitive to killing by the HOX/PBX antagonist HXR9. (a) HXR9 enters the cytoplasm and nuclei of PC3 cells in vitro. PC3 cells were incubated with 5 MM FITC labelled HXR9 (green) for two hours and then stained with Hoechst S769121 (a fluorescent dye staining nuclei yellow). Scale bar: $20 \mu \mathrm{m}$ (b-d) Light micrographs of PC3 cells either untreated (b) or incubated with $60 \mu \mathrm{M}$ CXR9 (c) or HXR9 (d) for two hours. Scale bar: 100 um (e) Survival curves for PC3, DU145, LNCaP and WPMY-1 cells treated with HXR9. (f) IC50 values for HXR9 treatment. The negative control peptide CXR9 was not toxic at any of the concentrations tested for any of the cell lines (i.e. the IC50 $>100 \mu \mathrm{M})$. Error bars represent the SEM $(n=3)$, the $p$ values are with respect to WPMY-1.
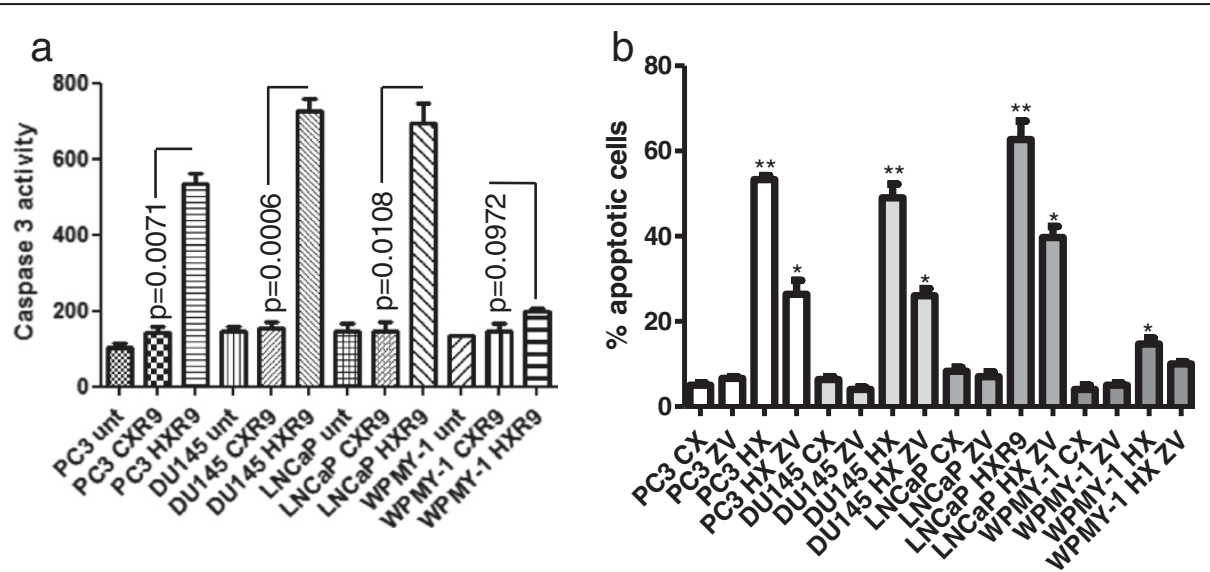

Figure 3 HXR9 induces apoptosis in prostate cancer cells. (a) Caspase 3 activity in PC3, DU145, LNCaP and WPMY-1 cells treated with 60 4M HXR9 or CXR9 for two hours. 'Unt' - untreated cells; Y axis units: relative fluorescence (b) PC3, DU145, LNCaP and WPMY-1 cells were treated with $60 \mu \mathrm{M}$ HXR9 (HX) or CXR9 (CX) for two hours and cells were assessed for apoptosis through Annexin/7AAD staining. The \% of cells in apoptosis is shown. Cells were also treated with the Caspase inhibitor ZVAD (ZV) alone or in combination with HXR9 (HX ZV). Error bars show the SEM. ${ }^{*} p<0.05,{ }^{* *} p<0.01$ with respect to untreated cells. 
integrity of cells, thus allowing cells to be divided into those undergoing early or late stage apoptosis depending on the relative binding of the two labels (Figure 3b). All of the cell lines tested had significantly increased levels of apoptosis after a two hour treatment with $60 \mu \mathrm{M}$ HXR9, compared to CXR9 treated cells. Apoptosis was considerably higher in the prostate cancer derived cell lines PC3, DU145 and LNCaP (10.6, 8.2 and 7.9 fold, respectively) than in WPMY-1 (3.8 fold).

To provide further confirmation that cells were undergoing apoptosis, HXR9 and CXR9 treated cells were also treated with $50 \mu \mathrm{M}$ Z-VAD, a caspase inhibitor that blocks the apoptotic cascade. This caused a significant reduction in the proportion of cells undergoing apoptosis (Figure 3b), with the exception of WPMY-1 cells.

\section{HXR9 induced cell death is mediated by cFos}

Previous studies have suggested that HXR9-induced apoptosis might be mediated by the elevated expression of the $c F o s$ gene $[19,21]$. To further explore this, and determine whether it is true for prostate cancer derived cells, we used QPCR to assess the expression level of cFos in HXR9 and CXR9 treated cells. A two hour treatment with $60 \mu \mathrm{M}$ HXR9 caused a 6.2, 10.3 and 19.1 fold increase in cFos levels in DU145, PC3 and LNCaP cells, respectively (Figure 4a). In contrast, no significant increase was observed in WPMY-1 cells.

In order to establish whether increased $c F o s$ levels were directly responsible for inducing cell death, we used a siRNA knock down strategy to reduce $c F o s$ expression in HXR9 treated cells. DU145 cells were transfected with a random control siRNA (rnd siRNA), or one of two different siRNAs designed against the cFos sequence (siRNA1/2). Pre-treatment of DU145 cells with either of the $c F$ os siRNAs was sufficient to block the increase in $c F o$ s expression upon subsequent treatment with HXR9, both at the mRNA and protein level (Figure $4 \mathrm{~b})$. This also resulted in a significant increase in
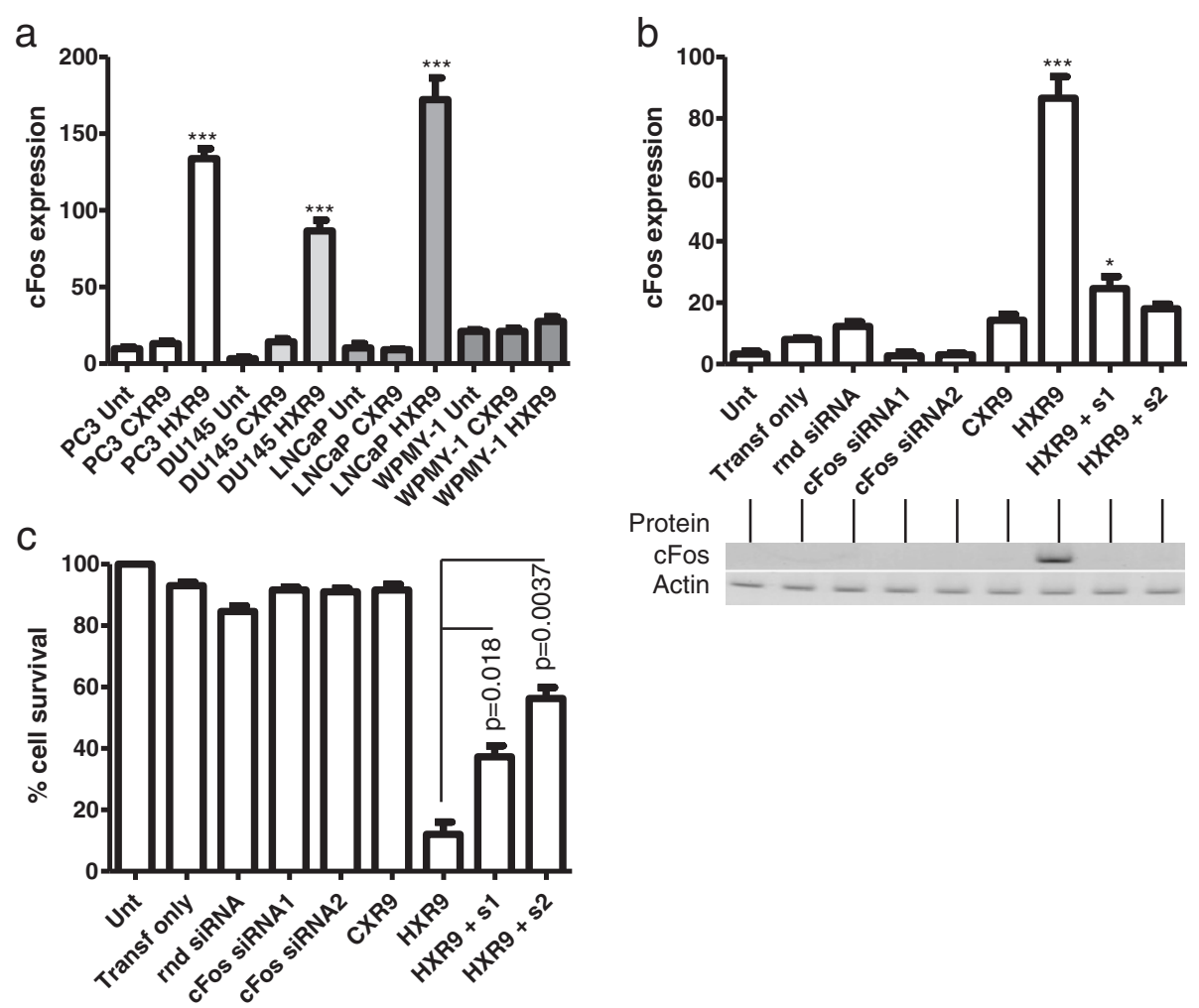

Figure 4 HXR9 induced apoptosis is mediated by cFos. (a) QPCR analysis of cFos expression in response to treatment of PC3, DU145, LNCaP and WPMY-1 cells with $60 \mu \mathrm{M}$ HXR9 or CXR9 for two hours. 'Unt' - untreated cells; CFos expression is shown as a ratio with the $\beta$-actin gene $(\times 10,000)$. (b) Knock down of CFos expression using siRNA. DU145 cells were incubated with transfection reagent alone ('Transf only'), or were transfected with a control siRNA with a random sequence ('rnd siRNA'), or with one of two siRNA targeting cFos ('cFos siRNA 1' and 'cFos siRNA $2^{\prime}$ ). Cells were also either treated with $60 \mu \mathrm{M}$ HXR9 or CXR9, or with HXR9 in combination with one of the transfected cFos specific siRNAs ('HXR9+ $s 1$ ' or 'HXR9 + s2'). The expression of cFos in treated cells was determined either at the RNA level using QPCR (upper section) or at the protein level using western blotting (lower section). (c) The \% cell survival for each of the treatments described in (b). Knock down of cFos in HXR9 treated cells results in a statistically significant decrease in cell death. Error bars show the SEM. ${ }^{*} p<0.05,{ }^{* * *} p<0.001$ with respect to untreated cells. 

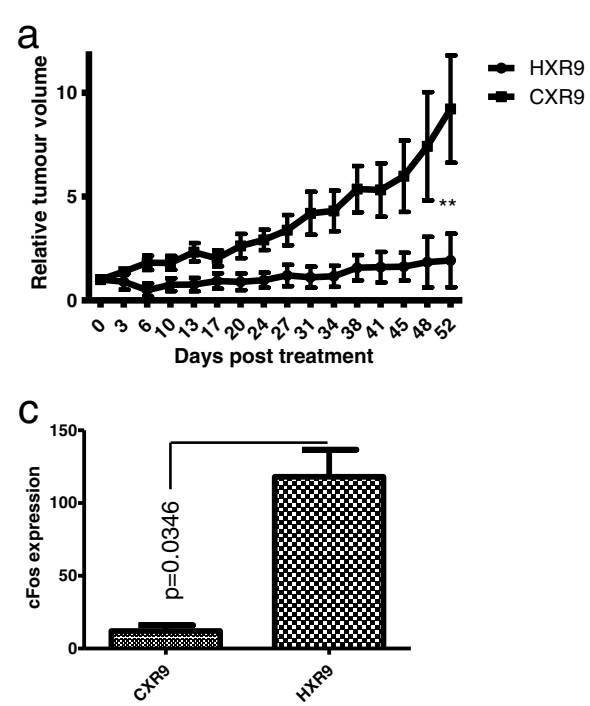

Figure 5 HXR9 retards LNCaP tumour growth in vivo. (a) Growth curve for LNCaP tumours treated intratumorally with a single dose of HXR9 (9 mice) or CXR9 (8 mice) when the tumour volume reached $100 \mathrm{~mm}^{3}$, followed by further doses if the tumour recurred. Error bars show the SEM. "Relative tumour volume" refers to the fold change in tumour size from the time of the first injection. (b) Top panels, sections through LNCaP tumours from mice treated with low dose $(1 \mathrm{mg} / \mathrm{Kg}$ ) FITC-HXR9. Top left, fluorescent view showing HXR9-FITC distribution (green). Top right, the same section under light microscopy. Scale bar: $100 \mu \mathrm{m}$. Bottom panels, sections through LNCaP tumours from mice treated with $100 \mathrm{mg} / \mathrm{Kg}$ HXR9 or CXR9. The CXR9 treated section shows highly undifferentiated tumour cells, whilst the HXR9 section shows the remains of dead tumour cells. Scale bar: 20 um. (c) Expression of CFos in tumours treated with HXR9 or CXR9 2 hours prior to their excision, shown as a ratio between cFos and GAPDH transcripts detected by QPCR (x10,000).

cell survival (from $12 \%$ in cells treated with HXR9 only, to $37 \%$ and $56 \%$ in cells pre-treated with $c$ Fos siRNA1 and cFos siRNA2, respectively; Figure 4c).

\section{HXR9 blocks the growth of LNCaP tumours in vivo}

The sensitivity of prostate cancer derived lines to killing by HXR9 in vitro prompted us to test whether this sensitivity was also apparent in vivo. We initiated flank tumours in nude mice using a subcutaneous injection of LNCaP cells, which have been used in numerous studies as a murine model of prostate cancer. Tumours were injected directly with HXR9 or CXR9 once the mean tumour volume had reached $100 \mathrm{~mm}^{3}$. After 52 days the CXR9 injected tumours had, on average, increased in size 8 fold, whilst the average increase in HXR9 tumours was 1.5 fold (Figure 5a). Histological analysis of tumours revealed that whilst CXR9 treated tumours were composed principally of live, highly undifferentiated cells, those injected with HXR9 contained relatively few cells and were composed to a large extent of cellular debris (Figure 5b). Treating mice with a low dose of fluorescently labelled HXR9 revealed a widespread take up of the peptide by the tumour cells (Figure 5b). QPCR analysis of RNA extracted from tumours revealed that HXR9 induces an up regulation of $c F o s$ in a similar manner to that seen in vitro, suggesting that a similar mechanism of cell death may occur (Figure 5c).

\section{HOX genes are globally overexpressed in primary prostate tumours}

As previous studies on $H O X$ gene expression in prostate cancer have focused only on single or small groups of genes, we undertook an analysis of all 39 HOX genes in prostate tumours and normal prostate tissue. This revealed a considerable over expression of many $H O X$ family members, albeit in a heterogeneous manner with different $H O X$ genes being overexpressed in different tumours. Only HOXC4 and HOXC6 showed consistently higher expression in the tumour compared to the normal prostate, with increases of 101 and 251 fold, respectively (Figure 6). Taking all of the HOX genes together also revealed a significantly higher global $H O X$ expression in tumours (11.9 fold, Figure 6).

\section{Discussion}

In this study we have shown that $H O X$ genes are highly deregulated in prostate tumours and in prostate cancer derived cell lines, which concurs with the findings of a number of previous studies [9-11]. It reveals that there is a very high level of deregulation with the majority of $H O X$ genes being highly expressed in tumours but not in normal prostate tissue. This global increase in $H O X$ expression makes it difficult to study those aspects of $H O X$ function that are redundant throughout this highly conserved group. Here we have used HXR9, an inhibitor 

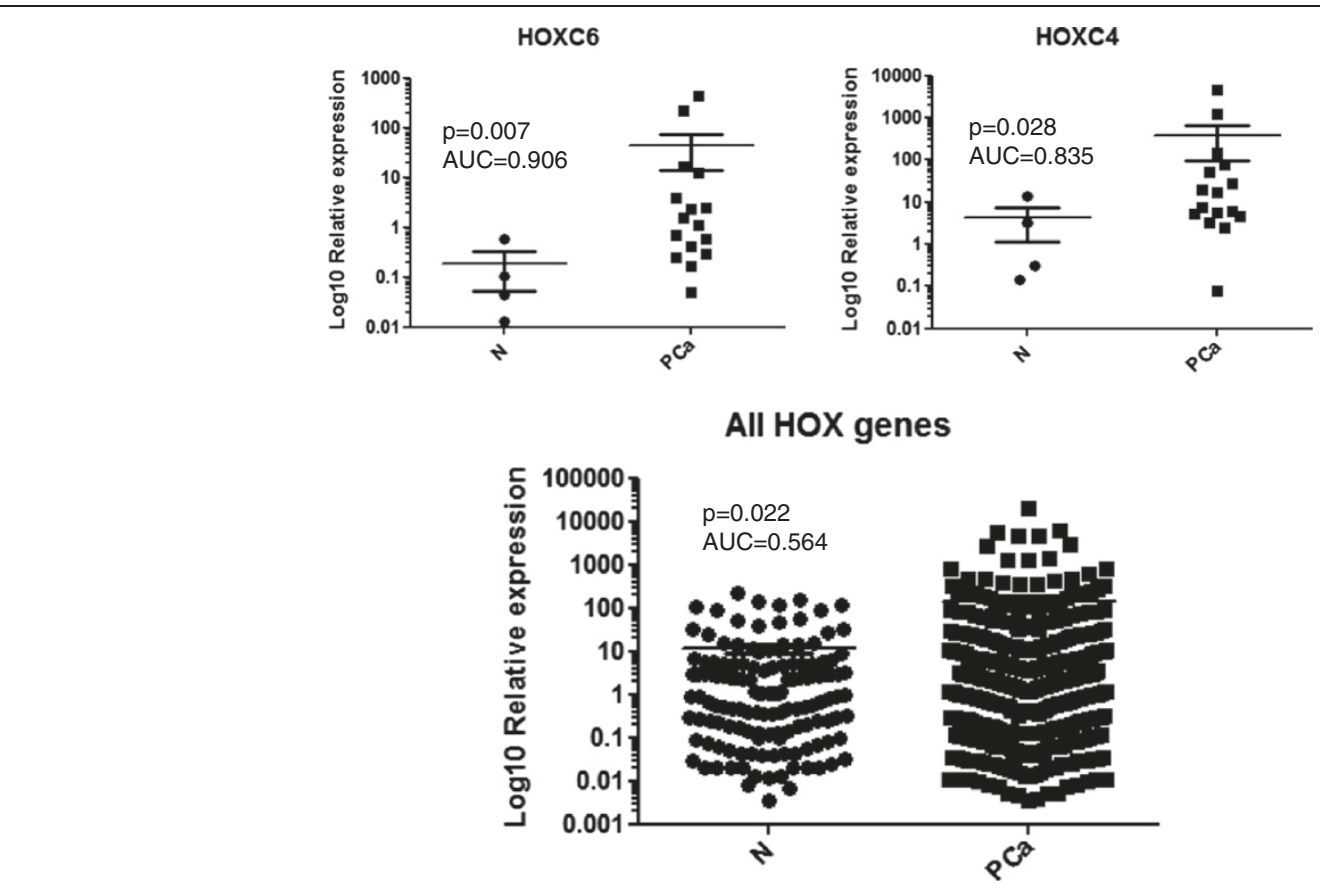

Figure 6 HOX gene expression in normal prostate tissue and prostate tumours. The expression of each gene was determined by semi-quantitative PCR and is shown relative to the house keeping gene GAPDH (x10000). The horizontal bar represents the mean and the error bars represent the SEM. AUC, area under the curve from a receiver-operator characteristics analysis.

of the interaction between HOX proteins and their common cofactor, PBX, to target a large subset of HOX proteins (i.e. members of paralogue groups 1-9) [19]. HXR9 causes apoptosis in all three of the prostate derived cells line studied, but only to a far lesser degree in a non-malignant cell line derived from prostate stroma (WPMY-1).

Disruption of $\mathrm{HOX} / \mathrm{PBX}$ regulated transcription would be expected to cause changes in the expression of numerous target genes, and indeed previous studies have shown this to be the case. However only one of these targets - cFos - has been shown to be directly relevant to the induction of apoptosis by HXR9 [19]. It was previously shown that cFos up-regulation mediated the HXR9-induced apoptosis in melanoma B16F10 cells, and here we show that a similar mechanism exists in the prostate cancer-derived cell lines DU145, PC3 and LNCaP, as siRNA knock-down of cFos can partially rescue each of these cell lines from HXR9 -induced cell death. Although $c F o s$ is classically considered to be an oncogene, there are now a number of reports of it acting as a pro-apoptotic gene [19,28-31]. Our observation that HXR9 results in a rapid and very large increase in $c F o s$ expression indicates that the HOX/PBX dimer acts as a repressor of this gene. Whilst this could be a direct result of $\mathrm{HOX} / \mathrm{PBX}$ binding to its regulatory sequences, a recent study showed that it could also be due to the increased transcription of the oncogenic microRNAs miR221 and mir222, which in turn repress $c$ Fos expression [16].

The prevalence of $H O X$ over expression in prostate cancer combined with the novel therapeutic mechanism exploited by HXR9 suggest that it could be a therapeutic approach where there is small volume, well defined disease. Local delivery of HXR9 into a range of tumours in mice has not resulted in a local inflammatory response $[18,20,21]$. Therefore delivery of HXR9 directly into the restricted confines of a primary or locally recurrent prostate cancer is feasible, and would not be limited due to the risk of prostatitis. Indeed a number of studies have evaluated intraprostatic gene therapy and oncolytic viral therapy and have reported no dose-limiting toxicity. These approaches utilised current imaging technology to achieve the precise delivery of reagents to small volume, well defined disease [32-34]. The application of HXR9 may be as a primary focal therapy, or where standard treatments approaches have failed, for example in cases of local recurrence following radical radiotherapy. The latter group of men currently receive ablative therapy which has low efficacy and is associated with significant toxicities [35]. In contrast to current treatments such as cryotherapy, the lack of inflammatory response associated with HXR9 treatment would potentially allow multiple, sequential intratumoral delivery. 


\section{Conclusions}

The HOX genes are highly dysregulated, and generally over-expressed in prostate cancer. Targeting the interaction between HOX proteins and their PBX co-factor is a potential therapeutic strategy in this malignancy.

\section{Competing interests}

The authors declare that they have no competing interests.

\section{Authors' contributions}

RM designed the study and wrote the manuscript. AB performed the cell viability assays and gene expression analysis. $\mathrm{KH}$ critically reviewed the manuscript and helped with experimental design. GS performed the in vivo experiments. AM assisted in the primary tissue collection and the analysis of gene expression in these samples. HP helped to design the study and to write the manuscript. All authors read and approved the final manuscript.

\section{Acknowledgment}

The authors gratefully acknowledge the support of the Prostate Project charity (UK)

\section{Author details}

${ }^{1}$ Faculty of Health and Medical Sciences, University of Surrey, Guildford, UK. ${ }^{2}$ Targeted Therapy Team, Chester Beatty Laboratories, The Institute of Cancer Research, London, UK

Received: 16 October 2013 Accepted: 30 January 2014

Published: 5 February 2014

\section{References}

1. Ferlay J, Shin HR, Bray F, Forman D, Mathers C, Parkin DM: Estimates of worldwide burden of cancer in 2008: GLOBOCAN 2008. Int I Cancer 2010, 127:2893-2917.

2. DiBlasio CJ, Malcolm JB, Hammett J, Wan JY, Aleman MA, Patterson AL, Wake RW, Derweesh IH: Survival outcomes in men receiving androgendeprivation therapy as primary or salvage treatment for localized or advanced prostate cancer: 20-year single-centre experience. BJU Int 2009, 104:1208-1214.

3. Mukherji D, Eichholz A, De Bono JS: Management of metastatic castrationresistant prostate cancer: recent advances. Drugs 2012, 72:1011-1028.

4. Shah N, Sukumar S: The HOX genes and their roles in oncogenesis. Nat Rev Cancer 2010, 10:361-371.

5. Chang CP, Brocchieri L, Shen WF, Largman C, Cleary ML: Pbx modulation of HOX homeodomain amino-terminal arms establishes different DNA-binding specificities across the HOX locus. Mol Cell Biol 1996, 16:1734-1745.

6. Knoepfler PS, Bergstrom DA, Uetsuki T, Dac-Korytko I, Sun YH, Wright WE, Tapscott SJ, Kamps MP: A conserved motif N-terminal to the DNA-binding domains of myogenic bHLH transcription factors mediates cooperative DNA binding with pbx-Meis1/Prep1. Nucleic Acids Res 1999, 27:3752-3761.

7. Morgan R, In der Rieden P, Hooiveld MH, Durston AJ: Identifying HOX paralog groups by the PBX-binding region. Trends Genet 2000, 16:66-67.

8. McGinnis W, Krumlauf R: Homeobox genes and axial patterning. Cell 1992, 68:283-302.

9. Miller GJ, Miller HL, van Bokhoven A, Lambert JR, Werahera PN, Schirripa O, Lucia MS, Nordeen SK: Aberrant HOXC expression accompanies the malignant phenotype in human prostate. Cancer Res 2003, 63:5879-5888

10. Norris JD, Chang CY, Wittmann BM, Kunder RS, Cui H, Fan D, Joseph JD, McDonnell DP: The homeodomain protein HOXB13 regulates the cellular response to androgens. Mol Cell 2009, 36:405-416.

11. Waltregny D, Alami Y, Clausse N, de Leval J, Castronovo V: Overexpression of the homeobox gene HOXC8 in human prostate cancer correlates with loss of tumor differentiation. Prostate 2002, 50:162-169.

12. Eklund EA: The role of HOX genes in malignant myeloid disease. Curr Opin Hematol 2007, 14:85-89.

13. Huang L, Pu Y, Hepps D, Danielpour D, Prins GS: Posterior HOX gene expression and differential androgen regulation in the developing and adult rat prostate lobes. Endocrinology 2007, 148:1235-1245.

14. Ando $\mathrm{H}$, Natsume A, Senga T, Watanabe R, Ito I, Ohno M, Iwami K, Ohka F, Motomura K, Kinjo S, Ito M, Saito K, et al: Peptide-based inhibition of the
HOXA9/PBX interaction retards the growth of human meningioma. Cancer Chemother Pharmacol 2014, 73:53-60.

15. Daniels TR, Neacato II, Rodriguez JA, Pandha HS, Morgan R, Penichet ML: Disruption of HOX activity leads to cell death that can be enhanced by the interference of iron uptake in malignant B cells. Leukemia 2010, 24:1555-1565

16. Errico MC, Felicetti F, Bottero L, Mattia G, Boe A, Felli N, Petrini M, Bellenghi M, Pandha HS, Calvaruso M, Tripodo C, Colombo MP, et al: The abrogation of the HOXB7/PBX2 complex induces apoptosis in melanoma through the miR221\&222-c-FOS pathway. Int J Cancer 2013, 133:879-892.

17. Li Z, Zhang Z, Li Y, Arnovitz S, Chen P, Huang H, Jiang X, Hong GM, Kunjamma RB, Ren $\mathrm{H}$, He C, Wang $\mathrm{CZ}$, et al: PBX3 is an important cofactor of HOXA9 in leukemogenesis. Blood 2013, 121:1422-1431.

18. Morgan R, Boxall A, Harrington KJ, Simpson GR, Gillett C, Michael A, Pandha HS: Targeting the HOX/PBX dimer in breast cancer. Breast Cancer Res Treat 2012, 136:389-398.

19. Morgan R, Pirard PM, Shears L, Sohal J, Pettengell R, Pandha HS: Antagonism of HOX/PBX dimer formation blocks the in vivo proliferation of melanoma. Cancer Res 2007, 67:5806-5813.

20. Morgan R, Plowright L, Harrington KJ, Michael A, Pandha HS: Targeting HOX and PBX transcription factors in ovarian cancer. BMC Cancer 2010, 10:89.

21. Plowright L, Harrington K, Pandha HS, Morgan R: HOX transcription factors are potential therapeutic targets in non-small-cell lung cancer (targeting HOX genes in lung cancer). Br J Cancer 2009, 100:470-475.

22. Shears L, Plowright L, Harrington K, Pandha HS, Morgan R: Disrupting the interaction between HOX and PBX causes necrotic and apoptotic cell death in the renal cancer lines CaKi-2 and 769-P. J Urol 2008, 180:2196-2201.

23. Stone KR, Mickey DD, Wunderli H, Mickey GH, Paulson DF: Isolation of a human prostate carcinoma cell line (DU 145). Int I Cancer 1978, 21:274-281.

24. Kaighn ME, Narayan KS, Ohnuki Y, Lechner JF, Jones LW: Establishment and characterization of a human prostatic carcinoma cell line (PC-3). Invest Urol 1979, 17:16-23.

25. Horoszewicz JS, Leong SS, Kawinski E, Karr JP, Rosenthal H, Chu TM, Mirand EA, Murphy GP: LNCaP model of human prostatic carcinoma. Cancer Res 1983, 43:1809-1818

26. Webber MM, Bello D, Quader S: Immortalized and tumorigenic adult human prostatic epithelial cell lines: characteristics and applications part 2. Tumorigenic cell lines. Prostate 1997, 30:58-64.

27. Workman P, Balmain A, Hickman JA, McNally NJ, Rohas AM, Mitchison NA, Pierrepoint CG, Raymond R, Rowlatt C, Stephens TC, et al: UKCCCR guidelines for the welfare of animals in experimental neoplasia. Lab Anim 1988, 22:195-201.

28. Sauvageau G, Lansdorp PM, Eaves CJ, Hogge DE, Dragowska WH, Reid DS, Largman C, Lawrence HJ, Humphries RK: Differential expression of homeobox genes in functionally distinct CD34+ subpopulations of human bone marrow cells. Proc Natl Acad Sci U S A 1994, 91:12223-12227.

29. Vider BZ, Zimber A, Hirsch D, Estlein D, Chastre E, Prevot S, Gespach C, Yaniv A, Gazit A: Human colorectal carcinogenesis is associated with deregulation of homeobox gene expression. Biochem Biophys Res Commun 1997, 232:742-748.

30. Kalra N, Kumar V: c-Fos is a mediator of the c-myc-induced apoptotic signaling in serum-deprived hepatoma cells via the p38 mitogenactivated protein kinase pathway. J Biol Chem 2004, 279:25313-25319.

31. Mikula M, Gotzmann J, Fischer AN, Wolschek MF, Thallinger C, Schulte-Hermann R, Beug H, Mikulits W: The proto-oncoprotein c-Fos negatively regulates hepatocellular tumorigenesis. Oncogene 2003, 22:6725-6738.

32. Patel P, Young JG, Mautner V, Ashdown D, Bonney S, Pineda RG, Collins SI, Searle PF, Hull D, Peers E, Chester J, Wallace DM, et al: A phase I/II clinical trial in localized prostate cancer of an adenovirus expressing nitroreductase with CB1954 [correction of CB1984]. Mol Ther 2009, 17:1292-1299

33. Sonpavde G, Thompson TC, Jain RK, Ayala GE, Kurosaka S, Edamura K, Tabata K, Ren C, Goltsov AA, Mims MP, Hayes TG, Ittmann MM, et al: GLIPR1 tumor suppressor gene expressed by adenoviral vector as neoadjuvant intraprostatic injection for localized intermediate or high-risk prostate cancer preceding radical prostatectomy. Clin Cancer Res 2011, 17:7174-7182.

34. Thirukkumaran CM, Nodwell MJ, Hirasawa K, Shi ZQ, Diaz R, Luider J, Johnston RN, Forsyth PA, Magliocco AM, Lee P, Nishikawa S, Donnelly B, et al: 
Oncolytic viral therapy for prostate cancer: efficacy of reovirus as a biological therapeutic. Cancer Res 2010, 70:2435-2444.

35. Chou R, Dana T, Bougatsos C, Fu R, Blazina I, Gleitsmann K, Rugge JB: Treatments for Localized Prostate Cancer: Systematic Review to Update the 2002 U.S. Preventive Services Task Force Recommendationed. Rockville (MD): Agency For Healthcare Research and Quality; 2011.

doi:10.1186/1471-2490-14-17

Cite this article as: Morgan et al:: Targeting HOX transcription factors in prostate cancer. BMC Urology 2014 14:17.

\section{Submit your next manuscript to BioMed Central} and take full advantage of:

- Convenient online submission

- Thorough peer review

- No space constraints or color figure charges

- Immediate publication on acceptance

- Inclusion in PubMed, CAS, Scopus and Google Scholar

- Research which is freely available for redistribution 